Bernard Herskovic

\title{
EFEITOS DE BUSCA EM CONLUIO
}

\section{Dissertação de Mestrado}

Dissertação apresentada ao Programa de PósGraduação em Economia da PUC-Rio como requisito parcial para obtenção do título de Mestre em Economia.

Orientador: Prof. Vinicius Nascimento Carrasco

Co-orientador: Prof. João Manoel Pinho de Mello 
Bernard Herskovic

Efeitos de busca em conluio

\author{
Dissertação de Mestrado
}

Dissertação apresentada ao Programa de PósGraduação em Economia da PUC-Rio como requisito parcial para obtenção do título de Mestre em Economia. Aprovada pela Comissão Examinadora abaixo assinada

Prof. Vinicius Nascimento Carrasco

Orientador

Departamento de Economia - PUC-Rio

Prof. João Manoel Pinho de Mello

Co-orientador Departamento de Economia - PUC-Rio

Prof. Leonardo Bandeira Rezende

Departamento de Economia - PUC-Rio

Prof. Afonso Arinos de Mello Franco Neto EPGE - Fundação Getúlio Vargas

Prof $^{a}$. Mônica Herz

Coordenadora Setorial do Centro de Ciências Sociais - Puc-Rio

Rio de Janeiro, 19 de Março de 2010 
Todos os direitos reservados. É proibida a reprodução total ou parcial do trabalho sem autorização do autor, do orientador e da universidade

\section{Bernard Herskovic}

Graduou-se em Ciências Econômicas pela Faculdade de Ciências Econômicas (FACE) da Universidade Federal de Minas Gerais (UFMG) em 2008.

Ficha Catalográfica

Herskovic, Bernard

Efeitos de busca em concluio / Bernard Herskovic ; orientador: Vinicius Nascimento Carrasco ; co-orientador: João Manoel Pinho de Mello. -2010.

52 f. : il. ; $30 \mathrm{~cm}$

Dissertação (Mestrado em Economia)Pontifícia Universidade Católica do Rio de Janeiro, Rio de Janeiro, 2010.

Inclui bibliografia

1. Economia - Teses. 2. Busca. 3. Conluio. 4. Jogos repetidos. I. Carrasco, Vinicius Nascimento. II. Mello, João Manoel Pinho de. III. Pontifícia Universidade Católica do Rio de Janeiro. Departamento de Economia. IV. Título. 


\section{Agradecimentos}

Ao meu orientador Professor Vinicius Nascimento Carrasco e ao coorientador Professor João Manoel Pinho de Mello, pelo estímulo, apoio e parceria.

Aos meus pais Jacques e Nicole, pela educação, apoio e incentivo.

À minha irmã Chantal, por me descontrair tanto com suas tirinhas quanto com suas brincadeiras.

À Clara pela paciência, pelo carinho, por tudo.

Aos meus amigos Elias, André, Cida e Gabriel.

Ao Maurício e ao Arthur, pelos vários conselhos ao longo do curso.

Aos meus colegas e amigos da PUC-Rio.

Aos professores que participaram da banca examinadora.

A todos os professores e funcionários do Departamento pelos ensinamentos e pela ajuda.

A todos os amigos e familiares que de uma forma ou de outra me estimularam ou me ajudaram.

Ao CNPq, à CAPES, ao Departamento de Economia da PUC-Rio e à PUCRio, pelos auxílios concedidos, sem os quais este trabalho não poderia ter sido realizado. 


\section{Resumo}

Herskovic, Bernard; Carrasco, Vinicius Nascimento; Mello, João Manoel Pinho de. Efeitos de busca em conluio. Rio de Janeiro, 2010. 52p. Dissertação de Mestrado - Departamento de Economia, Pontifícia Universidade Católica do Rio de Janeiro.

Pesquisar preços pode ser custoso para os consumidores. Este artigo investiga os efeitos de busca na formação de conluio por parte das firmas. Para identificar tais efeitos, constrói-se um jogo repetido no qual os consumidores pesquisam preços seqüencialmente e as firmas competem por preços no jogo estático. Claramente, identificam-se dois efeitos distintos, por um lado, mais busca, i.e. mais consumidores pesquisando preços ou um menor custo de busca, facilita a formação de conluio, pois as firmas sustentam punições críveis mais severas. Por outro lado, mais busca dificulta a formação de conluio à medida que os desvios do conluio se tornam mais lucrativos.

\section{Palavras-chave}

Busca, conluio, jogos repetidos. 


\section{Abstract}

Herskovic, Bernard; Carrasco, Vinicius Nascimento (Advisor); Mello, João Manoel Pinho de (Co-advisor). Search effects on collusion. Rio de Janeiro, 2010. 52p. Msc. Dissertation - Departamento de Economia, Pontifícia Universidade Católica do Rio de Janeiro.

This paper investigates, through a theoretical approach, search effects on collusion. In order to identify these effects, we consider an infinitely repeated game; in the stage game, consumers search for prices sequentially and firms set price simultaneously. We clearly identify two different search effects on collusion; on the one hand, it facilitates collusion as the punishment payoff is lower. On the other hand, it makes collusion more difficult, since deviations are more profitable.

\section{Keywords}

Search, collusion, repeated games. 


\section{Sumário}

1 Introdução 12

2 Jogo estático 16

$\begin{array}{ll}3 \text { Jogo repetido } & 19\end{array}$

4 Punição ótima 23

5 Conluio e busca 26

6 Firmas impacientes $\quad 29$

$\begin{array}{ll}7 \text { Exemplo } & 35\end{array}$

8 Interpretando o modelo como custo de troca 39

9 Considerações finais 41

10 Referências bibliográficas $\quad 44$

11 Apêndice $\quad 47$

11.1. Demonstrações $\quad 47$

11.2. Lucro esperado ex-ante 51 


\section{Lista de figuras}

Figura 1 - Lucro do equilíbrio de Nash e do conluio versus a taxa de desconto. $c=0,05$ e $\mu=0,5$.

Figura 2 - Taxa mínima de desconto para conluio com preço de monopólio versus proporção de consumidores com custo zero de busca. $c=0,05$.

Figura 3 - Taxa mínima de desconto para conluio com preço de monopólio versus custo de busca. $\mu=0,5$.

Figura 4 - Lucro de conluio por firma versus taxa de desconto para diferentes valores de $\mu . c=0,02$.

Figura 5 - Lucro de conluio por firma versus taxa de desconto para diferentes valores de $c . \mu=0,5$. 


\section{Lista de tabelas}

Tabela 1 - Efeitos de busca em conluio com preço de monopólio, considerando a punição de minmax.

Tabela 2 - Efeito de busca em conluio para firmas impacientes 
O senhor... Mire veja: o mais importante e bonito, do mundo, é isto: que as pessoas não estão sempre iguais, ainda não foram terminadas mas que elas vão sempre mudando. Afinam ou desafinam. Verdade maior. É o que a vida me ensinou. Isso que me alegra, montão.

Riobaldo

João Guimarães Rosa, Grande Sertão: Veredas 